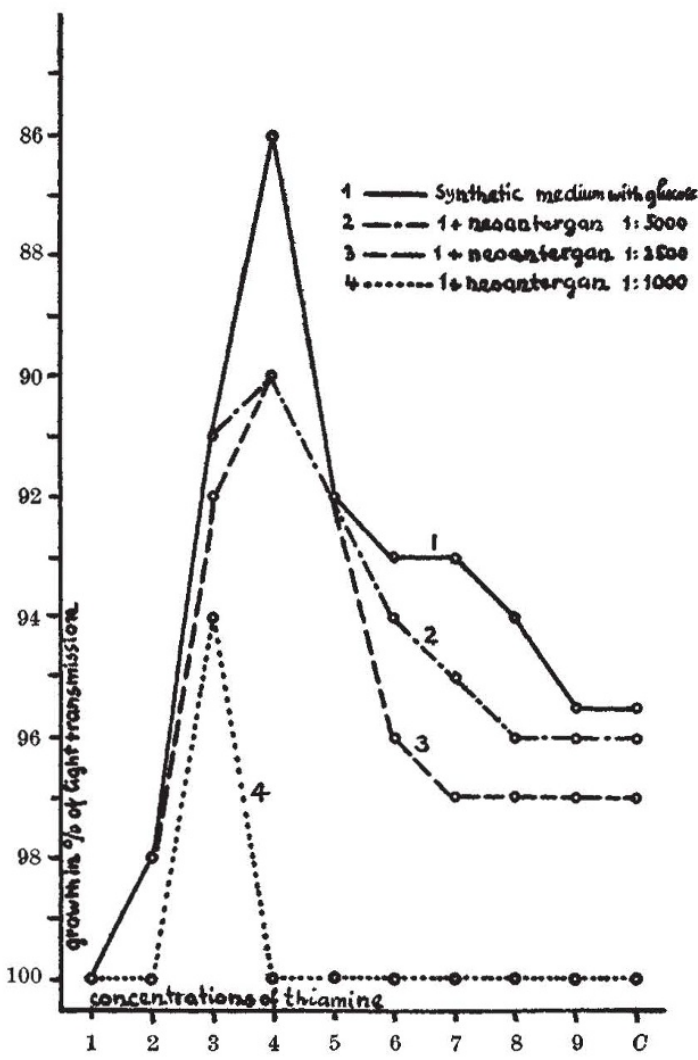

Fig. 2. Growth of strain 688 after $10 \mathrm{hr}$. culture in various concentrations of thiamine. Concentrations as in Fig. 1

effect of thiamine and histamine on the blocking effect of antihistamines on bacterial growth occurs only when bacteria utilize glucose as source of energy ; histamine and thiamine growth-promoting effects on bacteria have a similar quantitative relation to the suppressing effect of these substances on the bacteriostatic action of antihistamines.

Histamine acts in a similar way to thiamine in our bacterial strains, possibly as a coenzyme in the catabolism of glucose.

Institute for Medical Microbiology,

J. STTERZL

Charles University, Praha II.

Institute for Control and Research,

J. Ǩ̌Е̌̌EK

United Pharmaceutical Works, Prague.

May 13.

${ }^{1}$ Křecek, J., and Sterzl, J., Biol. Listy (in the press).

\section{Influence of Histamine on Nerve Block due to Anti-Histaminics}

Most of the anti-histaminic drugs are local anæsthetics ${ }^{1}$. Procaine, too, has an anti-histaminic action $^{2}$. Euler has demonstrated the presence of large amounts of histamine in certain nerves ${ }^{3}$. We have investigated the influence of histamine on the nerve block caused by procaine and some of the antihistaminics. In the frog nerve-muscle preparation, we have found that a nerve block caused by, for example, pyribenzamine can be removed by washing with a solution containing, besides the blocking concentration of the local anæsthetic, a certain concentration of histamine. If the nerve is placed in contact with the mixture of histamine and blocking agent solution, no block results even when the concentration of the blocking agent is quite sufficient for producing block if applied alone. Two typical experiments follow.

(1) Removal of block. The sheath of a nerve was removed for a stretch of about $7 \mathrm{~mm}$., and a solution of 0.25 per cent pyribenzamine in frog's Ringer solution was applied. Conduction was tested with short bursts of stimuli at 50 per sec. from a thyratron device. The nerve was blocked after $4 \mathrm{~min}$. The block was removed in $3 \mathrm{~min}$. by washing with frog's Ringer solution to which had been added 0.25 per cent pyribenzamine and 0.6 per cent histamine-dihydrochloride.

(2) Prevention of block. Two nerve-muscle preparations from the same frog were used. The sheaths of the nerve were left intact. Nerve $A$ was placed in 0.3 per cent procaine hydrochloride in frog's Ringer solution; nerve $B$ in 0.3 per cent procaine hydrochloride +0.4 per cent histamine-dihydrochloride in frog's Ringer solution. Nerve $A$ was blocked after 18 min., whereas nerve $B$ was still conducting after $100 \mathrm{~min}$.

This investigation is being continued.

Pharmacological Jnstitute,

\section{ERNST BÁRÁNY}

Peroy Nordqvist University, Uppsala.

$$
\text { May } 14 .
$$

1 Huttrer, Experientia, 5, 53 (1949).

${ }^{2}$ Frommel, Favre and Vallette, Arch. intern. Pharmacodyn., 73, 355 (1947).

s. Euler, J. Physiol., 107, 10P (1948).

\section{Presence of a Spasmogenic Substance, presumably Histamine, in Extracts of Mummy Tissue}

Egyptian mummies as well as mummified bodies from other parts of the world have been the subject of extensive investigation. Thus, for example, it has been possible to obtain blood-group reactions with mummified tissue, as shown by Boyd and Boyd', Candela $^{2}$ and Matson ${ }^{3}$. In the field of palæopathology, a term created by Ruffer ${ }^{4}$, the microscope has revealed the persistence of many characteristic cells and other histological features in sections of mummies and similarly treated bodies. In a recent investigation $^{5}$, I have even demonstrated, among other matters, the existence of red blood corpuscle remnants in ancient Swedish skeletons (Viking age), buried without the embalming procedures used in Egypt and elsewhere. Pictures of relatively well-preserved organic framework of bone tissue were obtained with material even from so early a period as the Upper Stone Age.

Various substances have been identified in mummified tissues by means of chemical methods. Schmidt ${ }^{6}$ studied the occurrence of products of fat cleavage, and Abderhalden and Brahm", Abderhalden and Weil ${ }^{8}$ reported observations on amino-acids. Several amino-acids were demonstrated after acid hydrolysis of mummy muscles, including histidine and considerable amounts of tyrosine. 